\title{
Modelling human performance within manufacturing systems design: from a theoretical towards a practical framework
}

\section{T S Baines and O Benedettini}

\section{Introduction}

In today's competitive marketplace, manufacturing systems have to be constantly designed and redesigned as organizations are continually being pressured to change their facilities, technologies, methods, people, and products. The effectiveness of these design processes depends on a reliance on accurate predictions about how the planned system will perform. Without accurate predictions at the design stage, it can be impossible to obtain the operational efficiency of production operations. This is a serious issue because of the enormous financial investments in modern manufacturing systems and the associated financial losses caused by the systems not performing as expected. Therefore, the purpose of the research presented in this paper has been to improve the process of manufacturing systems design by attempting to include a more accurate representation of workers' behaviour.

A lack of consideration of human issues has been cited as a major cause of deficiencies in the predictive accuracy of current manufacturing systems design approaches (Badham and Ehn, 2000). Despite the sophistication of automation technologies, 'direct work' (ie the presence of people who carry out somewhat repetitive manual production tasks) is still a necessary part of many manufacturing processes (Das, 1999). Moreover, as technology progresses and automated components become more and more efficient and reliable, the performance of human operators is increasingly critical. This importance of people in manufacturing is at present widely recognized (Youndt et al, 1996), but not yet supported by an adequate appreciation of human issues in manufacturing systems design approaches. Considerations concerning the human workforce tend to be made at a relatively late stage of the design process and are substantially limited to safety and ergonomics issues (Bonney et al, 2000). Manufacturing systems designers have a scant awareness of the complexity of the behaviour of people in their factories (Checkland, 1981; Packquet and Lin, 2003) and have been found to prioritize attention to technological elements of the systems (Guimares et al, 1999). As a consequence, current design approaches tend to disregard the fact that workers vary as they perform production tasks and the impact that this may have on the performance of the system. The problem is essentially generic as it is relevant to the design or redesign of any manufacturing system that involves a contribution from direct work.

A potential solution for this problem is to develop computer-based simulation. This technique enables analysis of how the system is likely to perform under conditions defined by the designer. Within simulation, the performance of the system is predicted by defining the behaviour of its elements. If the capability of a more accurate modelling of the human element can be developed, this would be a valuable means to improve the predictive accuracy of manufacturing systems design.

Developing such a capability is central to this paper. The work has been based on the theoretical framework for human performance modelling proposed by Baines et al (2005). It has focused on evolving this purely theoretical framework towards a practical modelling tool that can be incorporated into simulation models of manufacturing systems. The aim here has been to practically assess the viability of the theoretical framework and learning about the limitations of its approach so as to provide a platform for future research. Hence, this research is an essential step in the process of enabling human performance modelling in a practical way.

The paper first presents the need to more accurately model human performance in manufacturing systems design. Here, the theoretical framework of Baines et al (2005) is also described. On this basis, a three-phase research programme is set out. According to this programme, a field study is designed and executed which applies the theoretical framework to a selected industrial case. The results are used to evaluate strengths and weaknesses in the 
theoretical framework and then to propose developments in its formulation. The paper concludes with the final section summarizing areas for future research.

\section{Background}

\subsection{The industrial problem}

Manufacturing organizations need to improve both the efficiency and the flexibility of their operations continuously in order to meet ever-changing technologies and global market demands (Goldhar and Jelinek, 1983; Klingstam and Gullander, 1999). Achieving these goals is largely determined by how well their production processes or manufacturing systems are designed. At the design stage, evaluations and decisions can prevent many problems and defects that will directly affect the operational and fiscal efficiency of the systems (Fadier and Ciccotelli, 1999). This means that manufacturing systems design is a crucial endeavour through industry and needs to be constantly monitored and modified by manufacturing organizations (Holst and Bolmsjö, 2001; Cunha et al, 2003).

The purpose of designing or redesigning a manufacturing system is to define the most suitable production configuration from a range of possibilities. The task of a manufacturing systems designer is to consider all the different components that are necessary for a particular production process and to integrate them within the constraints of available space and resources so that they function synchronously and with optimal efficiency (Rachamadugu and Shanthikumar, 1991; Rao and Rao, 1997). This involves the consideration of many different issues such as layouts, methods, times, health and safety, ergonomics, and line balancing. To this end, the process of manufacturing systems design needs to integrate different interdependent functions (Slack et al, 2001) and is therefore inherently complex. Industrial engineers and managers involved in this task can now rely on a number of structured analysis techniques which can help to predict how the planned design or redesign is likely to perform when operational (Baines and Ladbrook, 2002). One of the most popular and valuable of these techniques is computer-based simulation (Shannon, 1998).

Computer-based simulation is centred on the construction of a computer model that reproduces the behaviour of the system. By running this model, the dynamic behaviour of the system can be observed over time, and its performance can be predicted by means of numerical indicators (Law and Kelton, 1991; Carrie, 1998).

The majority of simulation tools used in manufacturing, such as Witness, are based on the discrete event simulation (DES) technique (Davis, 1998; Chan and Jiang, 1999). It is quite easy within these models to consider many system variables and to reproduce dynamic interactions of resources and time dependence of activities. However, despite the sophistication of the technique, it has been observed that a gap can exist between the performance of the system as predicted by DES models and the output that the real system generates in practice (Freudenberg and Herper, 1998; Baines and Kay, 2002). One of the possible appearances for this gap is shown in Figure 1, with simulation providing and overoptimistic representation of reality (Siebers, 2004).

Figure 1 - Typical gap between simulation prediction and real system behaviour (adapted from Siebers, 2004).

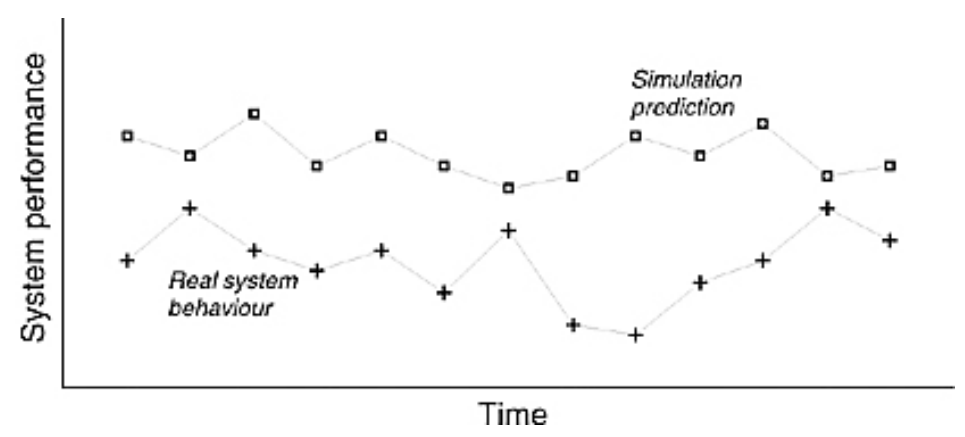

This particular situation has been found to occur to a wider extent when the systems contain more human elements (Baines and Kay, 2002). Practitioners tend traditionally to consider people quite simplistically and to prioritize prediction, planning and positioning of the technological elements of the systems. This has the implicit assumption 
that production workers are not able to exert significant variation in their performance because of the regulating effects of automated and mechanical processes in the systems. On this basis, people are treated as simple production resources, the presence of which may be a necessary condition for machines to operate. Their behaviour is defined, within simulation models, by the number, type, and skills of workers required for each machine, together with the conditions under which labour may be obtained by interrupting other processes. This 'resource concept' approach to model human operators is clearly limited (Bernhardt and Schilling, 1997; Baines and Kay, 2002).

In practice, people are rarely observed to behave regularly. They are rather inherently instable, unpredictable, and capable of independent actions (Checkland, 1981). Moreover, their performance is sensitive to numerous kinds of external influences and is subjected to several forms of decay in comparison to technological elements of the systems (Harrell et al, 2000). Therefore, a desirable improvement to simulation would be to incorporate a better representation of direct workers' performance into DES tools. To achieve this, the rules, assumptions, and relationships that define the behaviour of these particular entities need to be incorporated into models. It is not sufficient to simply 'allow' users to specify distributions of process times. Once all the relevant determinants are known, they can be embedded into DES tools. The research challenge is to identify these key behavioural characteristics.

\subsection{Development of a human performance modelling capability}

The work described in this paper has the basic premise that accuracy of DES models can be improved by modelling direct workers in a more sophisticated way. A more accurate representation of direct workers' behaviour could be provided within DES technique through a human performance modelling tool that integrates with computer-based simulation to give a holistic view of system performance (Baines and Kay, 2002; Baines et al, 2005).

Figure 2 illustrates the form that such a view would take within the process of manufacturing systems design. The human performance modelling tool is shown in the figure as passing information about worker performance to a DES model and taking information on the factors that influence this performance as an input. To create such a modelling tool requires, as mentioned earlier, an in-depth understanding of the determinants of worker behaviour. In other words, a framework is needed to capture the key rules, assumptions, and relationships. The construction of such a framework is very challenging as the nature of the problem is multidisciplinary and modelling of human behaviour at almost any level of abstraction is extremely complex. A theoretical framework has been proposed by Baines et al (2005) based on an extensive review of the literature. As this forms the starting point of the research in this paper, the remainder of this section provides a summary of the framework.

Figure 2. Human performance modelling as an aid in the process of manufacturing systems design (adapted from Baines and Kay, 2002).

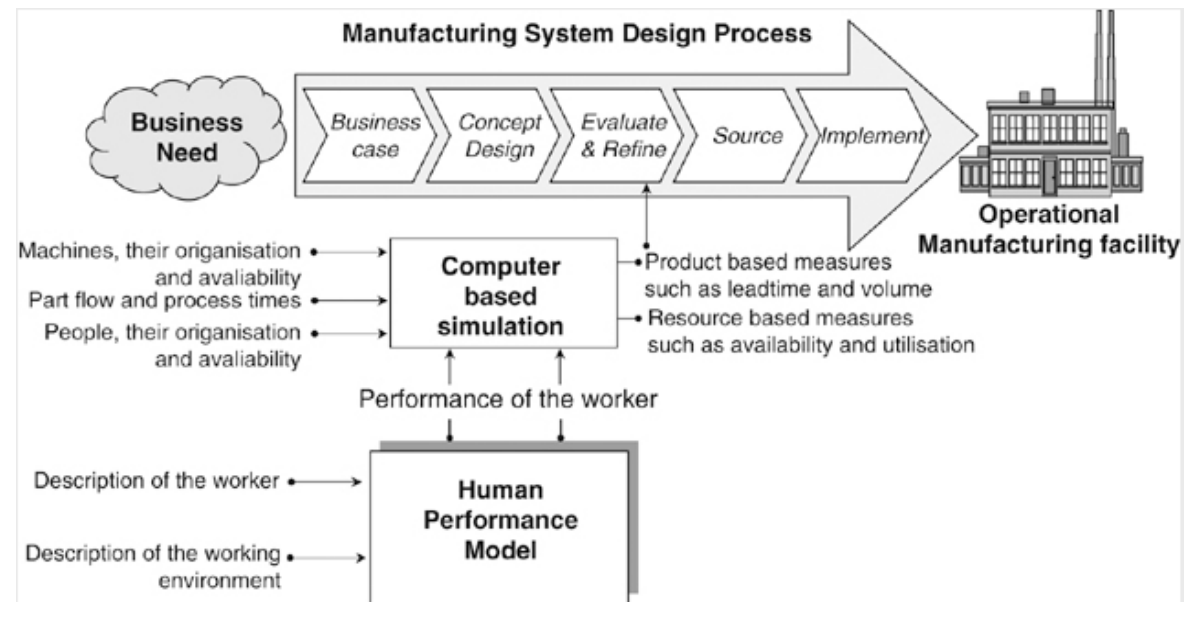




\subsection{A theoretical framework for human performance modelling}

In their framework (Figure 3), Baines et al (2005) regard the performance of the individual direct worker as a function of three categories of factors: factors relating to the personal characteristics of the worker, factors concerned with the physical working environment, and factors pertaining to the organizational working environment.

Figure 3. The theoretical framework for human performance modelling (adapted from Baines et al, 2005).

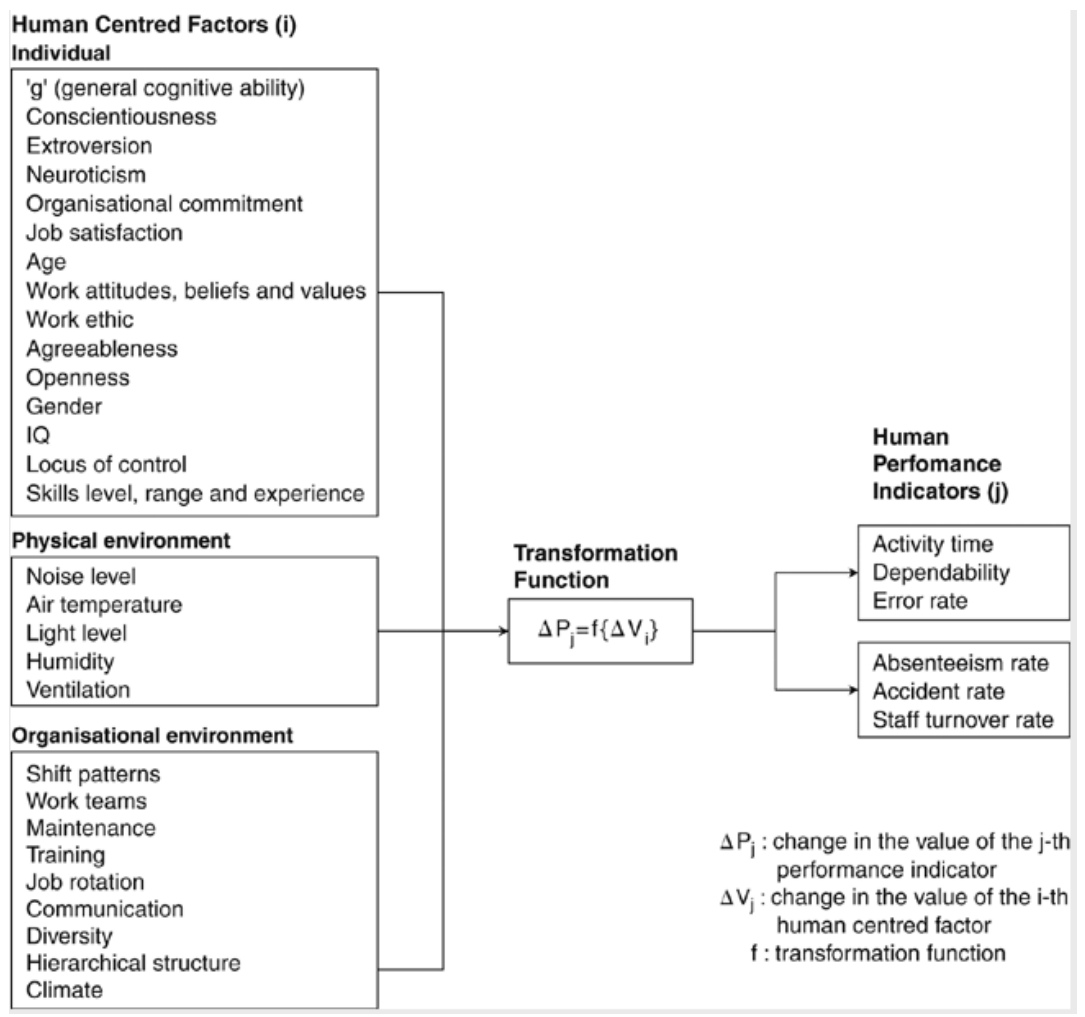

The framework concentrates on six performance outcomes. These are defined as measures of those variations in human performance that need to be considered in a simulation model of a manufacturing system to accurately represent direct workers. They include three major performance measures (dependability, activity time, error rate) and three additional measures (absenteeism rate, accident rate, staff turnover rate) that are necessary only if the simulation model is run over an extended period.

On this basis, the factors that determine human performance are regarded as the most important factors to affect the selected performance measures. The approach taken in the formulation of the framework was first to conduct an extensive literature research and by this to identify a large number of potential factors which, being related to either the individual worker, the physical or the organizational working environment, could impact on human performance. Then, the actual factors included in the framework were selected by assessing whether each of these potential factors was relevant to the context of manufacturing and to the performance measures in the framework, whether its impact on human performance was supported by robust evidence in the literature, and whether the factor could be measured in a reliable and consistent way. In the end, the theoretical framework includes 30 input factors. Factors depending on the individual worker range from psychological characteristics, to motivational attitudes, and to biographical data. Factors describing the physical working environment are measures of indoor air quality, of light and noise levels. Factors dealing with the organizational working environment are related to either the structure and culture of the host organization or to the human resources management practices (eg shift patterns, work teams).

The final element in the framework is the set of functional relationships that describe the effects on the performance measures of changes in the input factors. The framework includes a qualitative representation of these relationships in the form of a generic transformation function linking input factors and performance measures. 
An important comment that ought to be made is that the framework is a purely conceptual structure. At the present stage, it is not provided with exact specifications for the measurement of the input factors. In the same way, it does not suggest any quantitative modelling for the relationships between human-centred factors and performance. However, the framework offers a theoretical architecture around which a modelling tool can be developed. It has to be considered in the process of developing such a tool that the theoretical framework is based exclusively on literature research and collates a huge amount of literature from different disciplines. Therefore, it needs to be tested and revised in order to be workable in practice.

\section{Overview of the research programme}

The aim of the work described in this paper has been to progress research towards a practical modelling tool that enables effective representation of human performance within the process of manufacturing systems design. There is little doubt that this is a formidable task, but if some progress can be made, the consequences will be very significant. Here, our aim has not been to provide an exhaustive model of human performance but rather to explore and illustrate the approach that has to be taken in the formation of a modelling framework that can complement practical application. To achieve the aim, the following research objectives were identified, to:

1. Design and execute an experimental study providing practical application of the theoretical framework to an industrial case.

2. Analyse experimental results to establish strengths and weaknesses in the theoretical framework.

3. Propose developments to the theoretical framework and propose contributions towards enabling human performance modelling in practice.

The research methodology was structured to fulfil these objectives through a three-phase research programme. Phase 1 consisted of the operationalization of the theoretical framework on a selected industrial case and its application in a field experiment. This led to phase 2 analysing experimental results to evaluate how the framework works in practice. Then, phase 3 was conducted as using the output of phase 2 to identify improvements to the theoretical framework. The execution of phases 1,2 , and 3 is discussed in detail in the following three sections.

\section{Design and execution of the experimental study}

\subsection{Purpose and scope of the experimental study}

As summarized earlier, the theoretical framework was formed on the basis of a review of literature, and so the purpose here has been to explore how this theoretical framework can work in practice, to demonstrate its potential value, and to understand the challenges facing research in developing a more practical modelling tool. However, a number of simplifications and assumptions were made to enable this practical assessment. The scope of the study has been inevitably restricted by these reductions to an exploratory research.

\subsection{Selection of the industrial case}

Flow line systems were recognized as the most suitable study venue. They predominantly consist of repetitive tasks with short cycle times and, therefore, it is easy on these systems to have the opportunity to observe the same task for a large number of times. Identifying and gaining access to a suitable production plant was quite difficult. Unfortunately, due to the highly sensitive nature of this research work, the identity of the plant cannot be declared or described in detail.

The chosen production facility was an engine assembly line at the UK site of a major automotive manufacturer. This assembly line was divided into 10 main work zones that were all included in the study. Additional testing and finishing zones were not included because they only contained not repetitive manual operations. Engines travelled along the line on platens, which are special carriers acting as both material handling pallets and work holders during the operations. The transport of the platens was fully automated, with product units passing through all the zones in turn. Each zone included in the study contained a number of operations, which were performed by a team of workers varying in size from six to 12 people. Each individual in the team worked on all the operations in the zone, 
moving on to the next operation on an hourly basis. According to the exploratory nature of the study, it was decided to focus on a reduced number of operations. It was decided to monitor just one operation in each of the 10 work zones included in the study, the operation chosen being the one with the highest planned activity time. The plant operated $24 \mathrm{~h}$ a day, with three shifts each lasting $8 \mathrm{~h}$ and being manned by a specific crew of workers. Hence, performance data was collected for 12 weeks over these three shifts.

\subsection{Experimental design}

The setting of the study in an operational facility imposed a variety of practical limitations. These were mainly related to concerns raised by the management and by the unions as conditions for access. Firstly, the study was not allowed to affect assembly line productivity and to interfere with normal work performance. Secondly, the study was required not to disturb workforce sensitivity and hence not to collect any data which could be invasive of workers' privacy. Thirdly, data collection methods were imposed not to rely on the mass involvement of either the workers or the other personnel at the plant.

\subsection{Development of the data collection protocol}

The factors and performance in the theoretical framework are all measurable in principle. In practice, the contextual limitations described above impacted on the feasibility of collecting experimental data on some of these variables. Therefore, a number of simplifications were made to the theoretical framework during the study. This section focuses on these simplifications for both performance indicators and human-centred factors, and gives the rationale applied in each case.

\subsubsection{Establishing the indicators of worker performance.}

The most major simplification is that, of the six performance measures in the framework, the study only considered activity time in depth. Collecting data through direct observation of work performance should have allowed for a consideration of all the six performance measures, but this was discarded because of major objections from the workers. Furthermore, care would be needed to avoid the problems highlighted in the classic Hawthorne studies (Mayo, 1990). Direct observation was also impractical because of the need to observe workers for long periods of time in order to gather sufficient data. Therefore, it was decided to collect data through automated devices. To monitor activity times, electrical switches were installed underneath the workstations to record platen movements using digital event loggers. The unions agreed to this form of data collection, even though operators at individual work stations were not necessarily aware of whether or not their station was being monitored. This was conditioned on no direct linkage being made between activity time data and specific individuals.

\subsubsection{Establishing the human-centred factors}

Factors related to the physical environment were measured during the study. These were found to be nearly constant. A parallel study on the industrial case (Mason, 2004) had assessed that this consistency was such that there was no impact on activity time. Such evaluation was retained in our study and on this basis the physical environment measures were simply considered as control variables.

The assessment of the organizational environment was limited to the factors of shift and team, the remaining factors having been measured but again found to be constant in the study venue. Of these, training, maintenance, and job rotation reflected the way the assembly line was managed. The remaining factors, like hierarchical structure or climate, described the management culture. Therefore, variations of all these factors could potentially be observed only in the case of changes either in the human resources management practices or in the host organization, and none of these circumstances occurred during the study.

Finally, as for the factors related to the individual worker, the study concentrated on biographical data and on a set of factors which were explicitly related to the work context (ie work attitudes, beliefs, and values, goals, locus of control, organizational commitment, job satisfaction). All the other factors were representative of either psychological characteristics (eg conscientiousness, extroversion) or cognitive ability (ie general intelligence factor and IQ), and had to be excluded because their evaluation was only possible through psychological tests that were 
not accepted by the workers. The selected factors could instead be measured through methods that were much less invasive of workers' privacy.

The assessment of these factors was carried out in the study through attitude scales (Coolican, 1999) and implemented with an interview-based procedure. Attitude scales imply that the respondents are required to indicate their level of agreement or disagreement with a range of statements. Two sets of attitude scales were identified as providing the most suitable constructs to the motivational factors under assessment and are those from Warr et al (1979) and Cook and Wall (1980), as shown in Table 1. The attitude survey was also used to collect the biographical data of sex, age, and skill. In the absence of training differences between the workers, skill was evaluated as length of the employment service. The contents provided here for the design and execution of this survey were retained from the work in Fletcher (2004).

Table 1 - Attitude scales applied in the survey (adapted from Fletcher, 2004).

\begin{tabular}{|c|c|c|}
\hline Attitude scale & Content & Author \\
\hline Work involvement & 'The degree to which a person wants to be engaged in work' & $\begin{array}{l}\text { Warr et al } \\
(1979)\end{array}$ \\
\hline Intrinsic job motivation & 'The degree to which a person wants to work well in his or her job in order to achieve intrinsic satisfaction' & $\begin{array}{l}\text { Warr et al } \\
(1979)\end{array}$ \\
\hline $\begin{array}{l}\text { Perceived intrinsic job } \\
\text { characteristics }\end{array}$ & 'The person's reports about the degree to which features are present in his or her job which might give rise to intrinsic satisfaction' & $\begin{array}{l}\text { Warr et al } \\
(1979)\end{array}$ \\
\hline \multirow[t]{3}{*}{ Job satisfaction } & 'The degree to which a person reports satisfaction with intrinsic and extrinsic features of the job' & \\
\hline & - two subscales: intrinsic satisfaction, extrinsic satisfaction & $\begin{array}{l}\text { Warr et al } \\
(1979)\end{array}$ \\
\hline & - three further subscales: satisfaction with working conditions, satisfaction with the job itself, satisfaction with employee relations & \\
\hline \multirow{3}{*}{$\begin{array}{l}\text { Interpersonal trust at } \\
\text { work }\end{array}$} & 'The extent to which one is willing to ascribe good intentions and to have confidence in the words and actions of other people' & \\
\hline & - two subscales: trust in fellow worker, trust in management & $\begin{array}{l}\text { Cook and } \\
\text { Wall (1980) }\end{array}$ \\
\hline & - four further subscales: faith in fellow workers, confidence in fellow workers, confidence in management, faith in management & \\
\hline \multirow[t]{2}{*}{$\begin{array}{l}\text { Organizational } \\
\text { commitment }\end{array}$} & $\begin{array}{l}\text { 'A person's affective reactions to characteristics of his employing organization...feelings of attachment to the goals and values of the } \\
\text { organization, one's role in reaction to this, and attachment to the organization for its own sake rather than for its strictly instrumental } \\
\text { value' }\end{array}$ & \\
\hline & - three subscales: identification, involvement, loyalty & $\begin{array}{l}\text { Cook and } \\
\text { Wall }(1980)\end{array}$ \\
\hline
\end{tabular}

\subsection{Execution of the experimental study}

The execution of the study involved two parallel and interconnected data collection processes, one related to human performance and the other to the human-centred factors.

Human performance was concerned with activity time. Activity time was monitored on each of the 10 workstations $24 \mathrm{~h}$ a day, 5 days a week, over a 12-week period, generating approximately 150000 data points for each workstation monitored. Of the three crews of workers on the line during the study period, two were directly comparable. The third crew operated according to a different work pattern because it consisted of a smaller number of workers per team and some of them were required to perform more than one task. This meant that, although data were collected for this crew, they were not included in the analysis. In the end, the data collection considered two shifts and two teams for each of the 10 workstations, for a total of 260 workers involved in the study.

The collection of data on individual factors was based on the attitude survey. The monitoring of the organizational factors of shift and team was indeed an indirect outcome of the collection of activity time data. The survey was submitted to all the 260 workers on a voluntary basis. From this total sample pool, 111 workers participated.

\section{Results and discussion}

\subsection{Feasibility of the theoretical framework variables}

The practical arrangements for the data collection significantly reduced the formulation of the theoretical framework in the study. Firstly, the assessment of performance outcomes was limited by the need for an excessively complex measurement or of a over-long data collection campaign. However, the feasibility of practical application of the framework is supported by retaining activity time, which is the basic measure of human performance. Secondly, the factors related to the physical environment were evaluated as simply not relevant to the study. They only exhibited small variations during the data collection campaign and these were assessed to be unlikely to affect 
workers' performance. Similarly, the set of factors related to the organizational environment was drastically reduced as these factors were not subjected to change at the time of the study. Of them, only shift and team were considered, and this was because the way the assembly line was operated comprised different shifts and different teams of workers rotating on the same workstation. Finally, the appreciation of the factors related to the individual worker was affected by concerns from the unions and protecting workers' privacy. However, a number of individual attributes were identified which, being exclusively related to the work context, could be measured.

All these practical limitations, despite being introduced as specific to the study setting, are typical for an industrial organization. Therefore, they provide a fairly general evaluation of the process of applying the theoretical framework in practice. It could be possible in other organizations to gain access to a broader study venue, but the nature of restrictions affecting the data collection would remain unchanged.

\subsection{Assessment of the impact of the input factors on worker performance}

The data collected during the study were analysed in order to investigate the potential effect of the input factors on human performance. The approach was to use the statistical parametrical techniques of $t$-test and ANOVA.

These techniques were initially applied to compare the means of the grouped activity time data for different shifts and different teams. A t-test was used to assess whether there was significant difference between activity time data of the two shifts considered in the study. This pairwise comparison procedure was replaced by one-way ANOVA for the assessment of differences between teams, in a way to analyse the data of the 20 teams all at the same time. In both cases, in order to aggregate data across different workstations, the data was standardized into z-scores prior to the analysis. In addition, strength of results of the statistical analysis was investigated by calculating the 'effect size' (Cohen, 1988). This parameter allows to evaluate whether the results of a statistical analysis are affected by the size of the data sample: a 'small' effect size identifies statistical significance as effect of sample size, as opposite to a large effect size which instead recognizes statistical significance as independent of sample size. Statistical analysis showed a significant difference between activity time data for the two shifts [ $\mathrm{t}(211113)=-3.11, \mathrm{P}=<0.002]$ and for the 20 teams $[F(19.214202)=5854.0, P<0.0001]$ involved in the study. More precisely, this result demonstrates that the hypothesis of equal means for activity time data of different shifts and different teams could be rejected with a significance level of 99.80 and $99.99 \%$ ((1-P) times 100), respectively. This was calculated on the basis of the experimental data identifying the input values of 211113 and 19.24202 for the relevant Student's $(t)$ and Fisher's (F) distributions. However, a 'small' computed effect size [eta $=0.001]$ indicated that the impact of the shift on workers' performance cannot be relied upon.

The analysis of the effect of the factors related to the individual worker would have required us to group activity time data according to the characteristics of the individual performing the task. This was not possible, as performance data could not be linked to specific individuals. Therefore, the analysis was limited to the assessment of the magnitude of the differences between individual workers' activity times. Data pertaining to the same worker were grouped on the basis of the rotation pattern and a one-way ANOVA was performed on the standardized scores. It was found that difference between the scores of different individuals was statistically significant $[F(129.214062)=907.34, P<0.0001]$ or, in other terms, that the hypothesis of equal means for activity time data of different individuals could be rejected with a confidence level of $99.99 \%$. Moreover, a 'large' calculated effect size [eta $=0.35$ ] demonstrated that the result was not obtained as an effect of the size of the data set. This outcome was combined with the workforce profile that emerged from the attitude survey. For each of the attitude scales, the mean and the standard deviation of the scores of the sample population were found to be close to the normal and the standard deviation of the UK blue-collar population (Warr et al, 1979; Cook and Wall, 1980). The biographical information collected in the survey revealed a condition of sex disparity ( $91 \%$ of the workers were male), but an even distribution of both age and skill. These results indicate a differentiation of individual attitudes in the sample population. Clearly, the convergence of such a workforce profile with the presence of significant differences in individuals' activity times suggests that the individual factors in the framework may actually affect work performance. 


\subsection{Emergence of other input factors}

During the study, a number of factors emerged which seemed to affect workers' performance, but were not accounted for in the theoretical framework. For example, it was observed that self-pacing behaviours and task differences could cause performance variations but these were not accounted for in the theoretical framework because they were not considered in literature.

\section{Proposed recommendations and future work}

The work in the paper has addressed the aim to improve the capability of modelling human performance in the process of manufacturing systems design. It has proposed a first attempt to move research in the area from theory to practice. As a pilot study, it contains some methodological simplifications. A major one has been to neglect interactions between effects of different factors affecting worker performance and to analyse only the independent main effects. However, despite reductions and approximations, the work has a strong component in identifying the theoretical knowledge that best suits the modelling task and in providing a pragmatic assessment of such knowledge. On the basis of this assessment, we have confidence that it is possible to create a modelling tool to represent direct workers effectively within DES models, but this has to be based on a different approach. We believe that some clear indications on how to develop a better modelling framework have already emerged during this research, as discussed below.

First, the framework should focus on a smaller set of performance measures. The larger the number of performance measures in the framework, the larger is the number of relationships to investigate with the input factors. This research will need to be conducted in a real manufacturing environment and is likely to require collection of significant amounts of data about people and their behaviour. Our study has realized that such a measuring of human-related factors and performance is extremely difficult and necessitates exceptional time and effort. Therefore, it could be reasonable to attempt to concentrate on a very few performance measures. Our approach would be to prioritize those performance measures that have the most significant impact on system performance. This assessment is not available at the present stage of research yet, but we can hypothesize to reduce the framework to the three major performance measures of dependability, activity time, and error rate.

Secondly, the set of input factors needs to be revised. The variability of human performance that is relevant to the behaviour of manufacturing direct workers does not seem to be effectively described by the factors in the framework. For example, the conditions of the physical working environment were found to be constant in the study venue, but they would not have changed much in a different manufacturing setting as they are substantially imposed by Health and Safety Regulations. Furthermore, several of the organizational and individual factors that were not included in the study (eg cognitive ability, conscientiousness, communication, climate) could interfere with the execution of tasks requiring some decision making, but cannot reasonably be expected to be relevant to workers performing simple repetitive tasks, especially when these tasks are executed in a paced production line. The problem with the input factors in the framework is that their identification relies on literature and this does not appear to complement practical application. In such circumstances, it may be better to use empirical evidence to identify the determinants of worker performance. A possible scenario we can propose is to consider only three input factors, namely: the type of task, the type of system, and the suitability of the worker to the task. Different task types should be considered according to characteristics like the physical and mental effort required to the worker, the type of machinery and equipment used, the presence of incentives supporting performance improvement. The type of system should measure the flexibility given to the worker in carrying out the task or, equivalently, the constraints of automated processes. Moreover, the suitability of the worker to the task should differentiate a number of worker profiles that are relevant to each task type.

Finally, the work does give some useful guidance in the development of the transformation function in the framework. While relating input factors and performance, this function will be required to model variability trends that are intrinsic to human performance. A considerable amount of literature has argued that human performance is not constant under constant working conditions (eg Taylor, 1911), but can exhibit several types of trends, either 
deterministic or stochastic (eg Duley, 1955). On the basis of our study, we can suggest that the best approach to the formulation of the transformation function would not be to try to incorporate all these trends. Considering all the trends in literature would result in an exceptionally difficult modelling effort. Moreover, there is no guarantee that this would provide a feasible and efficient result. On the contrary, it can be observed that many of the trends have a very small impact on human performance and that a relevant part of the inherent variability in worker behaviour can be associated to only a few trends. A more reasonable approach seems, therefore, to be to focus on selecting a very limited number of these trends according to their impact on simulation accuracy.

\section{Conclusion}

This paper has set out to contribute to the development of a human performance modelling capability for manufacturing system designers. We have taken a largely deductive approach, in that a framework has been created from literature and then assessed in practice. We have recognized the exploratory nature of this research in the design of our study, and so favoured an in-depth study of a single plant over broader cross-company research. This work has enabled a dramatic change to our theoretical framework so that it can now be applied in practice. On the basis of this revision, our research will now proceed.

\section{References}

Badham R and Ehn P (2000). Tinkering with technology: Human factors, work redesign, and professionals in workplace innovation. Hum Factor Ergon Man 10: 61-82.

Baines TS, Asch L, Hadfield L, Mason JP, Fletcher S and Kay JM (2005). Towards a theoretical framework for human performance modelling within manufacturing systems design. Sim Model Pract Th 13: 486-504.

Baines TS and Kay JM (2002). Human performance modelling as an aid in the process of manufacturing system design: A pilot study. Int J Prod Res 40: 2321-2334.

Baines TS and Ladbrook J (2002). People, modelling their performance in manufacturing plants. In: Eldabi T, Robinson S, Taylor SJE and Wilcox PA (eds). Proceedings of the 2002 Operational Research Society Simulation Workshop. Operational Research Society, Birmingham, UK.

Bernhardt W and Schilling A (1997). Simulation of group work processes in manufacturing. In: Andradottir S, Nelson $B$ and Withers D (eds). Proceedings of the 1997 Winter Simulation Conference. IEEE Press: Piscataway, NJ, pp 888891.

Bonney M, Head M, Ratchev S and Moualek I (2000). A manufacturing system design framework for computer aided industrial engineering. Int J Prod Res 38: 4317-4327.

Carrie A (1998). Simulation of Manufacturing Systems. John Wiley \& Sons: New York.

Chan FTS and Jiang B (1999). Simulation-aided design of production and assembly cells in an automotive company. Integr Man Syst 10: 276-283.

Checkland PB (1981). Science and the systems movements. In: The Open University Systems Group (eds). Systems Behaviour. Harper and Row in association with The Open University Press: London, pp 26-43.

Cohen J (1988). Statistical Power Analysis for the Social Sciences, 2nd edn. Academic Press: New York.

Cook J and Wall T (1980). New work attitude measures of trust, organizational commitment and personal need nonfulfillment. J Occup Psychol 53: 39-52.

Coolican H (1999). Research Methods and Statistics in Psychology, 3rd edn. Hodder \& Stoughton: London. 
Cunha P, Dionisio J and Henriques E (2003). An architecture to support the manufacturing system design and planning. Int J Comput Integ M 16: 605-612.

Das B (1999). Development of a comprehensive industrial work design model. Hum Factor Ergon Man 9: 393-411.

Davis WJ (1998). Looking into the future of simulation. IIE Solutions 30: 24-30.

Duley NA (1955). Output patterns in repetitive tasks, PhD thesis, University of Birmingham.

Fadier E and Ciccotelli J (1999). How to integrate safety into design: Methods and models. Hum Factor Ergon Man 9: 367-379.

Fletcher S (2004). Understanding human variability to improve manufacturing system design, PhD thesis, Cranfield University.

Freudenberg R and Herper H (1998). Simulation of workers in manufacturing systems. In: Medeiros DJ, Watson EF, Carson JS and Manivannan MS (eds). Proceedings of the 1998 Winter Simulation Conference. IEEE Press: Piscataway, NJ, pp 951-956.

Goldhar JD and Jelinek M (1983). Plan for economies of scope. Harvard Bus Rev 61: 141-148.

Guimares T, Martensson N, Stahre J and Igbaria M (1999). Empirically testing the impact of manufacturing system complexity on performance. Int J Opns Prod Man 19: 1254-1269.

Harrell CR, Ghosh BK and Bowden R (2000). Simulation Using ProModel. McGraw-Hill: New York.

Holst $L$ and Bolmsjö G (2001). Simulation integration in manufacturing system development: A study of Japanese industry. Ind Mngt Data Syst 101: 339-356.

Klingstam P and Gullander P (1999). Overview of simulation tools for computer-aided production engineering. Comput Ind 38: 173-186.

Law AM and Kelton WD (1991). Simulation Modelling and Analysis. McGraw-Hill: New York.

Mason S (2004). Investigating the effects of the physical working environment upon direct manufacturing workers, PhD thesis, Cranfield University.

Mayo E (1990). Hawthorne and the western electric company. In: Pugh DS (ed). Organization Theory: Selected Readings. New York: Penguin Books, pp 345-357.

Packquet $V$ and Lin $L$ (2003). An integrated methodology for manufacturing systems design using manual and computer simulation. Hum Factor Ergon Man 13: 19-40.

Rachamadugu R and Shanthikumar JG (1991). Layout considerations in assembly line design. Int J Prod Res 29: 755768.

Rao GB and Rao SS (1997). Sector and age differences in productivity. Soc Sci Int 13: 51-56.

Shannon RE (1998). Introduction to the art and science of simulation. In: Medeiros DJ, Watson EF, Carson JS and Manivannan MS (eds). Proceedings of the 1998 Winter Simulation Conference. Piscataway, New Jersey: IEEE Press, pp 7-14.

Siebers PO (2004). The impact of human performance variation on the accuracy of manufacturing system simulation models, PhD thesis, Cranfield University. 
Slack N, Chambers S and Johnston R (2001). Operations Management, 3rd edn. Financial Times Prentice Hall: London.

Taylor FW (1911). The Principles of Scientific Management. Harper and Brothers: New York.

Warr P, Cook J and Wall T (1979). Scales for the measurement of some work attitudes and aspects of psychological well-being. J Occup Psychol 52: 129-148.

Youndt MA, Snell SA, Dean JW and Lepak DP (1996). Human resource management, manufacturing strategy, and firm performance. Acad Mngt J 39: 836-855. 